\title{
Cardiotoxicity associated with targeted cancer therapies (Review)
}

\author{
ZI CHEN ${ }^{1,2}$ and $\mathrm{DI} \mathrm{AI}^{3}$ \\ ${ }^{1}$ Department of Hematology, Huashan Hospital, Fudan University, Shanghai 200040, P.R. China; \\ ${ }^{2}$ Department of Hematopathology, University of Texas MD Anderson Cancer Center, Houston, TX 77030; \\ ${ }^{3}$ Department of Pathology, Baylor Scott and White Memorial Hospital, \\ Texas A\&M Health Science Center, Temple, TX 76508, USA
}

Received July 28, 2015; Accepted January 25, 2016

DOI: $10.3892 / \mathrm{mco} .2016 .800$

\begin{abstract}
Compared with traditional chemotherapy, targeted cancer therapy is a novel strategy in which key molecules in signaling pathways involved in carcinogenesis and tumor spread are inhibited. Targeted cancer therapy has fewer adverse effects on normal cells and is considered to be the future of chemotherapy. However, targeted cancer therapy-induced cardiovascular toxicities are occasionally critical issues in patients who receive novel anticancer agents, such as trastuzumab, bevacizumab, sunitinib and imatinib. The aim of this review was to discuss these most commonly used drugs and associated incidence of cardiotoxicities, including left ventricular dysfunction, heart failure, hypertension and thromboembolic events, as well as summarize their respective molecular mechanisms of cardiovascular adverse effects.
\end{abstract}

\section{Contents}

1. Introduction

2. Monoclonal antibodies to TKs

3. Small-molecule TKIs

4. Conclusion

\section{Introduction}

It has been nearly a century since the first drug treatment of cancer. Since then, chemotherapy has become a powerful tool for controlling malignancy, with significant benefits in terms of survival (1). Chemotherapy is also one of the most commonly used cancer therapeutics in modern medicine, along with radiation therapy and surgery (1). Traditional chemotherapy agents, such as alkylating agents and antimetabolites,

Correspondence to: Dr Di Ai, Department of Pathology, Baylor Scott and White Memorial Hospital, Texas A\&M Health Science Center, 2401 S. 31st Street, Temple, TX 76508, USA

E-mail: dai@sw.org

Key words: tyrosine kinase inhibitor, trastuzumab, bevacizumab, imatinib, sunitinib eliminate rapidly dividing cells, including not only tumor cells, but also normal tissue cells, such as those in digestive endothelia, hair follicles and bone marrow. This non-specific targeting treatment is associated with a broad range of side effects, including gastrointestinal (GI) symptoms, alopecia and even lethal adverse effects, such as bone marrow suppression. These negative effects significantly limit the applications of traditional agents and unnecessarily compromise the quality of life of cancer patients. In targeted cancer therapy, drugs interfere with key signaling molecules and inhibit tumorigenesis and metastasis, with fewer associated adverse effects (2).

In the human kinome, 90 of the 518 kinases are tyrosine kinases (TKs) (3) which play a central role in maintaining homeostasis, such as cell growth, differentiation, migration and apoptosis $(4,5)$. Mutations of TKs transduce aberrant signaling into cells and result in tumor growth and/or metastasis. Novel cancer strategies target key TKs and have been proven to be a remarkable achievement in cancer management. The two main categories of agents used in targeted cancer therapy are TK antibodies and TK inhibitors (TKIs).

Cardiotoxicity, a commonly encountered adverse effect, may be associated with traditional as well as novel targeted chemotherapeutic agents, and is grouped into two categories, namely type I (traditional) and type II (targeted), based on distinct pathological changes and clinical characteristics. Anthracyclines are the prototype of type I agents. Anthracycline-based chemotherapy is associated with a significant risk of left ventricular dysfunction (LVD) or congestive heart failure (CHF), compared with non-anthracycline regimens [odds ratio $(\mathrm{OR})=5.43$; 95\% confidence interval (CI): 2.34-12.62, $\mathrm{P}<0.0001]$ (6). The incidence of subclinical LVD may be as high as $36 \%$ in patients with a history of prior anthracycline therapy (7). Type I agents cause irreversible ultrastructural damage to cardiomyocytes, such as vacuole formation, contractile element disarray, or even necrosis (8). Trastuzumab is the representative agent in the type II category, resulting in cardiac dysfunction with an incidence reportedly ranging from 3 to $64 \%$ in single-agent or combination regimens (Table I). Type II agents result in benign ultrastructural changes in cardiomyocytes, with reversible cardiac function changes (8-10). In addition to cardiac dysfunction, targeted cancer therapy-induced cardiotoxicities may manifest as elevated blood pressure, thromboembolism, 
pericardial thickening and arrhythmia. The aim of this review was to discuss the representative drugs in targeted cancer therapy, the monoclonal antibodies to TKs (trastuzumab and bevacizumab) and small-molecule TKIs (sunitinib and imatinib).

\section{Monoclonal antibodies to TKs}

\section{Trastuzumab}

Background.Human epidermal growth factor receptor 2(HER2) is a $185-\mathrm{kd}$ transmembrane glycoprotein receptor, encoded by the ErbB2 proto-oncogene. Overexpression of HER2 promotes tumorigenesis in a variety of cancers, such as breast and colon cancer (11-13). Being a humanized monoclonal antibody against human HER2 with reduced immunogenicity, trastuzumab is highly effective in treating primary as well as metastatic breast cancer, thereby improving survival. Trastuzumab was the first Food and Drug Administration (FDA)-approved therapeutic antibody targeting molecular markers in cancer; it may be used as first-line therapy in combination with paclitaxel chemotherapy, and also as a single agent for patients who have priorly received chemotherapeutic regimens (14).

Cardiotoxicity incidence and molecular mechanism. Trastuzumab was a significant breakthrough in the treatment of breast cancer overexpressing HER2 receptors ( 25-30\% of breast cancers) (15). Cardiac dysfunction, either asymptomatic (decreased LV ejection fraction) or symptomatic (CHF), has been reported in pivotal phase II and III clinical trials, with a range from 3 to $64 \%$ when used alone or as part of combination regimens (Table I) $(8,16,17)$. Trastuzumab significantly increases the incidence of cardiotoxicity when combined with other agents. For example, in clinical trial H0648g, anthracycline and trastuzumab-treated patients experienced cardiac dysfunction at a rate of $27 \%$, compared with a rate of $8 \%$ in patients treated with anthracyclines alone (18-20). In the majority of the cases (79\%), the cardiac dysfunction improved after receiving treatment for heart failure (18), and reintroducing trastuzumab after recovery from cardiac dysfunction is considered acceptable (21). Trastuzumab is also safe when administered concurrently with postoperative radiotherapy, without an increased risk of cardiac events (22). Although there is no consensus on the onset of cardiotoxicity, it appeared that administering trastuzumab for $>6$ months was more likely to lead to a decline in the ejection fraction, whereas shorter treatment ( $\leq 6$ months) did not appear to be associated with an increased risk of heart failure.

Due to the limited biopsy samples, the mechanism of cardiotoxicity caused by trastuzumab treatment is not fully understood; however, inhibition of HER2 in cardiomyocytes may be the main mechanism underlying decreased cardiac function. Selective inactivation of ErbB2 in mouse ventricular myocardium revealed no overt developmental heart phenotype; however, on subsequent analysis, we observed dilated cardiomyopathy and a $\leq 50 \%$ reduction in fractional shortening. Furthermore, isolated neonatal cardiomyocytes from ErbB2 mutants in culture were more sensitive to adriamycin treatment, with apoptosis being more prominent in mutant hearts (23-26). All these data suggest that ErbB2 signaling is required to maintain adult cardiac function. However, the low incidence of cardiotoxicity with lapatinib (dual inhibition of
HER2 and epidermal growth factor receptor) and pertuzumab (another HER2 antibody) makes this possibility more obscure and debatable (27-30). Recently, Fedele et al reported that their newly synthesized anti-ErbB2 antibody, Erb-hcAb, recognizes a different epitope in HER2 than trastuzumab, without cardiac function alterations in their preclinical trial (31). The downstream targets mitogen-activated protein kinases (Erk1 and Erk2) and Akt activation were preserved in cardiac cell lines when treated by Erb-hcAb, but lowered in trastuzumab- or pertuzumab-treated cells. These findings suggest that trastuzumab causes cardiotoxicity by binding to a unique epitope in HER2 and blocks the Erk/Akt singling pathway (31). Other mechanisms that cause tumors to shrink are as follows: (i) Prevention of HER2 receptor dimerization and inhibition of downstream signaling pathways; (ii) recruitment of immune effector cells and subsequent tumor cell death; (iii) downregulation of the HER2 receptor $(32,33)$.

\section{Bevacizumab}

Background. Several types of tumor cells secrete angiogenic molecules, such as vascular endothelial growth factor (VEGF), to promote new vessel formation in order to meet the increased demands on oxygen and nutrients. By blocking VEGF/VEGF receptor (VEGFR) signaling, bevacizumab was the first FDA-approved humanized monoclonal anti-VEGF antibody to treat metastatic malignancies, including metastatic colorectal cancer (34) and non-squamous, non-small-cell lung cancer (35). In addition to bevacizumab, the FDA-approved small molecules that target VEGFR include lapatinib, sunitinib and sorefenib (Table I). The downstream targets of VEGF/VEGFR include phosphoinositide 3-kinase (PI3K)/Akt/protein kinase (PK) B and PKC/Erk, all of which are critical for endothelial cell survival and proliferation (36).

Cardiotoxicity incidence and molecular mechanism. Cardiotoxicity was observed in several clinical trials, although bevacizumab is not as widely used as trastuzumab (Table I). The three most commonly reported cardiovascular adverse effects are hypertension (HTN), CHF and thromboembolism. In rare instances, myocardial infarction was reported (37). The incidence of bevacizumab-related HTN was reported to be $16-47 \%$ in several clinical trials $(38,39)$ and it appears to be dose-dependent (40). When bevacizumab was used together with irinotecan, fluorouracil and leucovorin in metastatic colorectal cancer, the incidence of grade $3 \mathrm{HTN}$ increased by 8 points $(41,42)$. HTN associated with bevacizumab may be effectively controlled by an angiotensin-converting enzyme (ACE) inhibitor (43). As a rare adverse effect, $\mathrm{CHF}$ was reported in $\sim 1.7-3 \%$ of patients following bevacizumab treatment. The incidence of CHF was higher among patients with prior anthracycline treatment, cardiomyopathy, or chest wall irradiation (44-46). Thromboembolism is another severe adverse effect of bevacizumab treatment and the combination of bevacizumab and chemotherapy increases the risk of arterial thromboembolic events (hazard ratio $=2.0$, 95\% CI: $1.05-3.75, \mathrm{P}=0.31)$ more than chemotherapy alone. Prior arterial thromboembolic events and age $>65$ years were also reported as risk factors (37). Bevacizumab was also reported to be associated with the development of venous thromboembolism in cancer treatment (relative risk $=1.33$, 95\% CI: $1.13-1.56, \mathrm{P}<0.001)$. The type of tumor is associated 


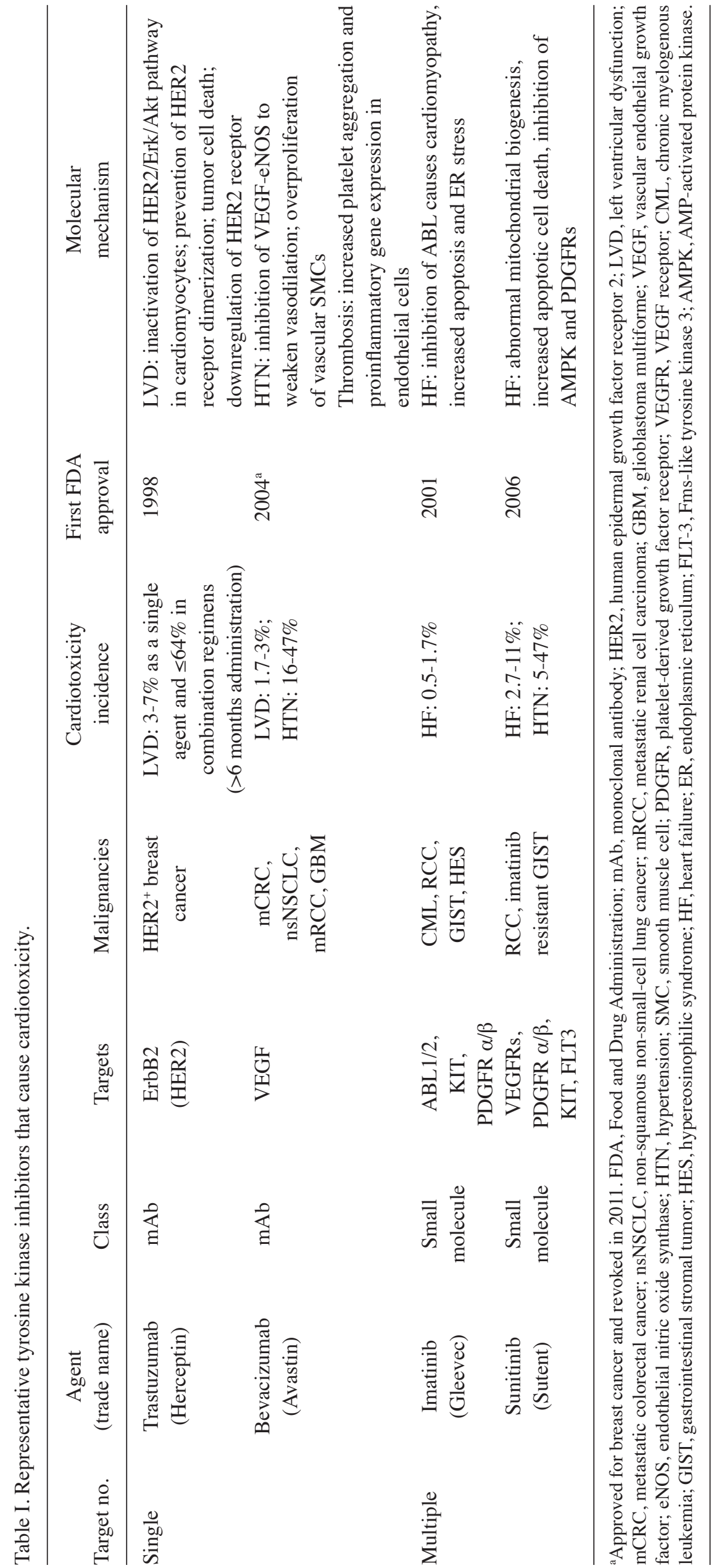


with venous thromboembolism and the dose of bevacizumab is another potential risk factor (47).

The molecular mechanisms through which bevacizumab causes these cardiovascular adverse effects are not well understood, but inhibition of the VEGF signaling pathway may play an important role. VEGF exerts a vascular protective effect in the adult vasculature; it may inhibit vascular smooth muscle cell (SMC) proliferation and promote endothelial cell survival. In addition, VEGF upregulates the expression of endothelial nitric oxide synthase (eNOS). Bevacizumab-induced HTN is possibly caused by: (i) Weakened vasodilation due to lowered NO production; and (ii) increased vascular resistance due to overproliferation and/or hyperplasia of vascular SMCs $(48,49)$. According to preclinical findings, VEGF has the ability to inhibit platelet aggregation by increasing $\mathrm{NO}$ and prostacyclin production, and chronic exposure to VEGF may decrease proinflammatory gene expression in endothelial cells, such as cyclooxygenase 2 and E-selectin (50-52). This may explain the arterial or venous thromboembolic events during bevacizumab treatment. Although the mechanisms underlying the development of CHF are not clearly understood, the elevated mean arterial blood pressure during bevacizumab treatment may predispose to CHF, particularly in those patients who had prior anthracycline treatment, cardiomyopathy, or chest wall irradiation. Furthermore, Izumiya et al reported that, in an animal model, a decoy VEGFR promoted LV dilatation and contractile dysfunction in the presence of pressure overload (53).

\section{Small-molecule TKIs}

The concept that ATP analogues may block the catalytic site of receptor tyrosine kinase (RTK) in cancer cells has been applied to design small-molecule TKIs, all of which exhibit very high affinity for the ATP pockets of the TK, so that the substrate protein cannot get access to the kinase site or be phosphorylated. The risk of TKI-associated cardiotoxicity is relatively low and well tolerated (54). We herein discuss two representative drugs, namely sunitinib and imatinib. Small molecules are tentatively considered as type II agents, due to the reversibility of the adverse effects and lack of cumulative dose-dependent effects. However, more biopsy data are required to confirm this classification (8). On-target cardiotoxicity is considered to be the main mechanism underlying imatinib-induced cardiotoxicity. On-target cardiotoxicity occurs when the therapeutic drug functions on the intended target, while off-target cardiotoxicity is observed when the TKI inhibits kinases other than the intended target (55). The representative drug of off-target cardiotoxicity is sunitinib (56).

\section{Imatinib mesylate}

Background. BCR-ABL is present in $>90 \%$ of chronic myeloid leukemia (CML) cases $(57,58)$. ABL is a non-receptor TK, and a fusion product, BCR-ABL, increases the TK activity of ABL. In CML cells, BCR-ABL activates a variety of signaling pathways, such as RAS, PI3K-Akt and signal transducer and activator of transcription $5 \mathrm{~A}$, to promote proliferation and prevent apoptosis (59). Imatinib is a revolutionary drug for the treatment of CML by targeting ABL (60); it efficiently inhibits $\mathrm{BCR}-\mathrm{ABL}^{+} \mathrm{CML}$ cells, blocks phosphorylation and induces apoptotic cell death. Anti-apoptotic factors, such as B-cell lymphoma 2 (Bcl-2) and Bcl-xL, are inhibited. Although imatinib cannot cure CML, it converts CML into a manageable, chronic disease. The best known imatinib targets are ABL, KIT and PDGFRs ( $\alpha$ and $\beta$ ).

Cardiotoxicity incidence and molecular mechanism. Imatinib has been approved by the FDA as an oral drug for the treatment of CML, gastrointestinal stromal tumors (GISTs) and hypereosinophilic syndrome. Overall, imatinib is well tolerated. Although the incidence of edema and dyspnea are reported to be as high as 66 and 16\%, respectively (57), LVD was overlooked during the first few years that imatinib was in the market $(60,61)$, until Kerkela et al reported 10 new-onset CHF cases in their study (57). Atallah et (62) reviewed 1,276 patients with hematological malignancies who were receiving imatinib, and found that 22/1,276 (1.7\%) had CHF symptoms; however, only 8 cases were considered possibly associated with imatinib treatment. Several other groups revealed the similarly low incidence of this adverse effect, with a range of $0.5-1.7 \%(62,63)$. Overall, imatinib-induced cardiotoxicity is a very uncommon adverse event. For those with a prior history, cardiac function should be closely followed up. Beta blockers, ACE inhibitors and diuretics may be used in the management of CHF (62-66).

Kerkela et al (57) reported that heart biopsy samples from 2 of $10 \mathrm{CHF}$ patients exhibited dilated sarcoplasmic reticulum with membrane whorls, and abnormal mitochondria with effaced cristae using transmission electron microscopy, which is usually seen as pathological changes in toxin-induced myopathies, as opposed to ischemic myopathy. Biopsies from imatinib-treated mice exhibited similar pathological changes. Since ABL protects against apoptosis, terminal deoxynucleotidyl transferase dUTP nick end labeling (TUNEL) assay was performed on mouse cardiomyocytes. In in vivo as well as in vitro experiments, the TUNEL assay revealed an increase in apoptosis. However, in imatinib-treated cell cultures, pronounced cytosolic vacuolization and loss of sarcolemmal integrity were observed, both of which are considered the hallmark of necrotic cell death, strongly suggesting that, besides apoptosis, necrotic death also plays an important role in this event $(57,60)$.

Further investigation using imatinib-treated cardiac cells revealed that, by inhibiting ABL, imatinib induced endoplasmic reticulum stress by activating PK RNA-like ER kinase, $\mathrm{PKC} \delta$ and inositol-requiring enzyme 1 pathways. All these events caused release of $\mathrm{Bcl}-2$-associated $\mathrm{X}$ protein and were followed by mitochondrial depolarization, ATP depletion, cytochrome $c$ release and eventually resulted in necrotic and apoptotic cell death (57). To circumvent ABL-induced cardiotoxicity, Fernández et al (67) modified imatinib by suppressing BCR-ABL inhibition and maintained its inhibition on c-Kit kinase. This new agent maintains the selective anticancer effects on GIST cells in vivo and in vitro, with a reduction of cardiotoxicity $(67,68)$. In addition, imatinib may affect cardiac progenitor cells in the human heart by blunting c-Kit, which is preserved in this cell group (69).

\section{Sunitinib}

Background. Sunitinib is a multiple TK inhibitor, with $>50$ known targets, including VEGFR 1-3, PDGFR $\alpha$ and $\beta$ and RET (70). Sunitinib is the first TKI approved by the 
FDA to be used in two different cancers, namely GIST and metastatic renal cell carcinoma ( $\mathrm{mRCC})$, with significant survival benefits (71). The antitumor mechanism of sunitinib is as follows: In tumor cells, sunitinib simultaneously inhibits the VEGFR/PI3K/mammalian target of rapamycin signaling pathway, RET, KIT, Fms-like tyrosine kinase 3 and their mutual downstream target, signal transducer and activator of transcription 3, to induce tumor cell apoptosis and growth arrest. Angiogenesis was also found to be inhibited by blocking the autocrine and paracrine effects of PDGFR in breast cancer cell lines (72-74).

Cardiotoxicity incidence and molecular mechanism. Sunitinib is overall well-tolerated and its adverse events are considered as manageable. The most common adverse events in sunitinib-treated patients are HTN and CHF. The incidence of sunitinib-associated CHF ranges from 2.7 to $15 \%(16,17,75)$. Motzer et al (76) investigated 750 patients with $\mathrm{mRCC}$ in a phase III trial of sunitinib; the incidence of grade 3 reduction in LV ejection fraction was similar in the two groups ( 2 and $1 \%$, respectively). In another research study on imatinib-resistant GIST, 8 of the $75(11 \%)$ patients receiving imatinib had a cardiovascular event and 6 of the $75(8 \%)$ patients had CHF (16); furthermore, $12(18 \%)$ had elevated troponin levels. This incidence is higher compared with that reported by other groups, possibly because patients in this study had received prior anticancer treatment (all their patients had been priorly treated with imatinib and 15 of the 75 patients had an anthracycline treatment history). Furthermore, the blind observation of time-to-CHF in the Chu et al study (16) was longer compared with that in Demetri et al study (77), namely 33.4 vs. 10 weeks, respectively. This may also explain the discrepancy between these two groups and suggests that a longer exposure to sunitinib may be required for patients to develop CHF $(16,76,76)$. Abnormal mitochondrial biogenesis was observed on transmitted electron microscopic examination, including membrane whorls and efface cristae in sunitinib-treated mice (16). In sunitinib-cultured neonatal rat ventricular myocytes, cytochrome $c$ was released, caspase-9 was activated and apoptotic death was detected by the TUNEL assay (16). Kerkela et al (56) reported an off-target mechanism of inhibition of AMP-activated protein kinase (AMPK). AMPK is a cellular energy generation switch. When cellular energy levels decrease, AMPK is activated to stimulate ATP production through catabolic pathways, while inhibiting energy-consuming pathways. Similar mitochondrial abnormalities, such as swollen mitochondria and effaced cristae, were observed in sunitinib-treated RCC patients and sunitinib-treated mouse hearts. Sunitinib induces myocyte loss in animal models. Loss of myocytes may be prevented by gene transfer of a constitutively active mutant AMPK, suggesting it was directly inhibited by sunitinib and results in energy compromise (56).

Cell surface RTKs-PDGFRs are important factors regulating cell proliferation and cell differentiation. PDGFRs are also expressed in cardiomyocytes and are unregulated in response to mechanical stress. PDGFRs are known sunitinib targets and inhibition of PDGFRs has been reported to play a protective role in hearts exposed to ischemic injury (78). However, PDGF/PDGFR signaling functions were investigated by treating cardiac tissue or post-myocardial infarction tissue with exogenous PDGF-B. However, the direct PDGFRs functions have not been elucidated. Chintalgattu et al (79) selectively blocked PDGFR-B in mice hearts and reported that, in PDGFR-B mutant mice, cardiac function was compromised and angiogenesis was impaired. These results demonstrated that PDGFR-B is required to maintain cardiac function in response to mechanical stress, and also for stress-induced cardiac angiogenesis. PDGFR-B regulates the heart and plays a positive role in maintenance; it is also required for angiogenesis and preservation of cardiac function in the presence of stress overload (79). This may be an off-target effect of sunitinib.

HTN is another cardiovascular toxicity associated with the administration of sunitinib. The incidence of this adverse event is $\sim 17-43 \%$. Of note, HTN was found to be a biomarker of efficacy in patients with $\mathrm{mRCC}$ treated with sunitinib. Patients with mRCC and sunitinib-induced HTN had better outcomes compared with those without treatment-induced HTN (80). The mechanism underlying the development of HTN has not been fully elucidated.

\section{Conclusion}

Targeted cancer therapy inhibits specific key molecules in tumors and is associated with fewer severe adverse effects. However, cardiotoxicity induced by this type of agent is not uncommon in clinical practice. To the best of our knowledge, there is no relevant literature investigating the survival benefit of targeted anticancer agents that cause cardiotoxicities. Although there is no consensus or guideline for evaluating or monitoring cardiac dysfunction, the cardiac function of high-risk patients who are scheduled for intermediate/high-risk surgery should be thoroughly investigated according to the American College of Cardiology/American Heart Association guidelines (81). New imaging technologies, such as three-dimensional echocardiography and speckle tracking imaging are emerging and may be used as surveillance of patients who are predisposed to cardiac dysfunction. As the application of targeted therapies in the treatment of cancer is on the increase, extensive research is required to understand in detail the mechanisms underlying the development of cardiovascular toxicities and promote the design of optimal drugs.

\section{Acknowledgements}

The authors would like to thank Ms. Chandler Carroll for the revision of the manuscript and the valuable suggestions.

\section{References}

1. DeVita VT Jr and Chu E: A history of cancer chemotherapy. Cancer Res 68: 8643-8653, 2008.

2. Sawyers C: Targeted cancer therapy. Nature 18: 294-297, 2004.

3. Manning G, Whyte DB, Martinez R, Hunter T and Sudarsanam S: The protein kinase complement of the human genome. Science 298: 1912-1934, 2002.

4. Prenzel N, Fischer OM, Steit S, Hart S and Ullrich A: The epidermal growth factor receptor family as a central element for cellular signal transduction and diversification. Endocr Relat Cancer 8: 11-31, 2001.

5. Slichenmyer WJ and Fry DW: Anticancer therapy targeting the erbB family of receptor tyrosine kinases. Semin Oncol 28 (5 Suppl 16): 67-79, 2001.

6. Smith LA, Cornelius VR, Plummer CJ, Levitt G, Verrill M, Canney $\mathrm{P}$ and Jones A: Cardotoxicity of anthracycline agents for the treatment of cancer: Systematic review and meta-analysis of randomized controlled trails. BMC Cancer 10: 337, 2010. 
7. van Dalen EC, Michiels EM, Caron HN and Kremer LC: Different anthracycline derivates for reducing cardiotoxicity in cancer patients. Cochrane Database Syst Rev: CDOO5006, 2010.

8. Ewer MS and Ewer SM: Cardiotoxicity of anticancer treatments: What the cardiologist needs to know. Nat Rev Cariol 7: 564-575, 2010.

9. Billingham ME, Mason JW, Bristow MR and Daniels JR: Anthracycline cardiomyopathy monitored by morphologic changes. Cancer Treat Rep 62: 865-872, 1978.

10. Bristow MR, Thompson PD, Martin RP, Mason JW, Billingham ME and Harrison DC: Early anthracyline cardiotoxicity. Am J Med 65: 823-832, 1978.

11. Slamon DJ, Clark GM, Wong SG, Levin WJ, Ullrich A and McGuire WL: Human breast cancer: Correlation of relapse and survival with amplification for the HER-2/new oncogene. Science 235: 177-182, 1987

12. Schuell B, Gruenberger T, Scheithauer W, Zielinski Ch and Wrba F: HER 2/new protein expression in colorectal cancer. BMC Cancer 6: 123, 2006

13. Latif Z, Watters AD, Bartlett JM, Underwood MA and Aitchison M: Gene amplification and overexpression of HER2 in renal cell carcinoma. BJU Int 89: 5-9, 2002.

14. Jelovac D and Emens LA: HER2-directed therapy for metastatic breast cancer. Oncology (Williston Park) 27: 166-175, 2013.

15. Cardinale D, Colombo A, Torrisi R, Sandri MT, Civelli M, Salvatici M, Lamantia G, Colombo N, Cortinovis S, Dessanai MA, et al: Trastuzumab-induced cardiotoxicity: Clinical and prognostic implications of troponin I evaluation. J Clin Oncol 28: 3910-3916, 2010

16. Chu TF, Rupnick MA, Kerkela R, Dallabrida SM,Zurakowski D, Nguyen L, Woulfe K, Pravda E, Cassiola F, Desai J, et al: Cardiotoxicity associated with tyrosine kinase inhibitor sunitinib. Lancet 370: 2011-2019, 2007.

17. Shaikh AY and Shih JA: Chemotherapy-induced cardiotoxicity. Curr Heart Fail Rep 9: 117-27, 2012.

18. Seidman A, Hudis C, Pierri MK, Shak S, Paton V, Ashby M, Murphy M, Stewart SJ and Keefe D: Cardiac dysfunction in the trastuzumab clinical trials experience. J Clin Oncol 20: 1215-1221, 2002

19. Slamon DJ, Leyland-Jones B, Shak S, Fuchs H, Paton V, Bajamonde A, Fleming T, Eiermann W, Wolter J, Pegram M, et al: Use of chemotherapy plus a monoclonal antibody against HER2 for metastatic breast cancer that overexpresses HER2. N Engl J Med 344: 783-92, 2001

20. Guarneri V, Lenihan DJ, Velaro V, Durand JB, Broglio K, Hess KR, Michaud LB, Gonzalez-Angulo AM, Hortobagyi GN and Esteva FJ: Long-term cardiac tolerability of trastuzumab in metastatic breast cancer: The M.D. Anderson cancer center experience. J Clin Oncol 24: 4107-4115, 2006.

21. Ewer MS, Vooletich MT, Durand JB, Wood ML, Davis JR, Valero V and Lenihan DJ: Reversibility of trastuzumab-related cardiotoxicity: New insights based on clinical course and response to medical treatment. J Clin Oncol 23: 7820-7826, 2005

22. Halyard MY, Pisansky TM, Dueck AC, Suman V, Pierce L, Solin L, Marks L, Davidson N, Martino S, Kaufman P, et al: Radiotherapy and adjuvant trastuzumab in operable breast cancer: Tolerability and adverse event data from the NCCTG phase III trial N9831. J Clin Oncol 27: 2638-2644, 2009.

23. Garratt AN, Ozcelik C and Birchmeier C: ErbB2 pathways in heart and neural diseases. Trends Cardiovasc Med 13: 80-86, 2003.

24. Negro A, Brar BK and Lee KF: Essential roles of Her2/erbB2 in cardiac development and function. Recent Prog Horm Res 59: $1-12,2004$

25. Crone SA, Zhao YY, Fan L, Gu Y, Minamisawa S, Liu Y, Peterson KL, Chen J, Kahn R, Condorelli G, et al: ErbB2 is essential in the prevention of dilated cardiomyopathy. Nat Med 8: 459-465, 2002

26. Ozcelik C, Erdmann B, Pilz B, Wettschureck N, Britsch S Hübner N, Chien KR, Birchmeier C and Garratt AN: Conditional mutation of the ErbB2 (HER2) receptor in cardiomyocytes leads to dilated cardiomyopathy. Pro Natl Acad Sci USA 99: 8880-8885, 2002.

27. Burris HA III, Hurwitz HI, Dees EC, Dowlati A, Blackwell KL, O'Neil B, Marcom PK, Ellis MJ, Overmoyer B, Jones SF, et al: Phase I safety, pharmacokinetics, and clinical activity study of lapatinib (GW572016), a reversible dual inhibitor of epiderma growth factor receptor tyrosine kinases, in heavily pretreated patients with metastatic carcinomas. J Clin Oncol 23: 5305-5313, 2005 .
28. Geyer CE, Forster J, Lindquist D, Chan S, Romieu CG, Pienkowski T, Jaqiello-Gruszfeld A, Crown J, Chan A, Kaufman B, et al: Lapatinib plus capecitabine for HER2-positive advanced breast cancer. N Engl J Med 355: 2733-2743, 2006

29. Gianni L,Lladó A, Bianchi G, Cortes J, Kellokumpu-Lehtinen PL, Cameron DA, Miles D, Salvagni S, Wardley A, Goeminne JC, et al: Open-label, phase II, multicenter, randomized study of the efficacy and safety of two dose levels of peruzumab, a human epidermal growth factor receptor 2 dimerization inhibitor, in patients with human epidermal growth factor receptor 2-negative metastatic breast cancer. J Clin Oncol 28: 1131-1137, 2010.

30. Perez EA, Koehler M, Byrne J, Preston AJ, Rappold E and Ewer MS: Cardiac safety of lapatinib: Pooled analysis of 3689 patients enrolled in clinical trials. Mayo Clin Proc 83: 679-686, 2008.

31. Fedele C, Riccio G, Malara AE, D'Alessio G and De Lorenzo C: Mechanisms of cardiotoxicity associated with ErbB2 inhibitors. Breast Cancer Res Treat 134: 595-602, 2012.

32. Clynes RA, Towers TL, Presta LG and Ravetch JV: Inhibitory Fc receptors modulate in vivo cytotoxicity against tumor targets. Nat Med 6: 443-446, 2000.

33. Gennari R, Menard S, Fagnoni F, Ponchio L, Scelsi M, Tagliabue E, Castiglioni F, Villani L, Magalotti C, Gibelli N, et al: Pilot study of the mechanism of action of preoperative trastuzumab in patients with primary operable breast tumors overexpressing HERS2. Clin Cancer Res 10: 5650-5655, 2004.

34. Van Cutsem E, Lambrechts D, Prenen H, Jain RK and Carmeliet P: Lessons from the adjuvant bevacizumab trial on colon cancer: What next? J Clin Oncol 29: 1-4, 2011

35. Jardim DL, Gagliato Dde M, Ribeiro KB, Shimada AK and Katz A: Bevacizumab as first-line therapy in advanced non-small-cell-lung cancer: A Brazillian center experience. Drugs R D 12: 207-216, 2012.

36. Rini BI: Vascular endothelial growth factor-targeted therapy in renal cell carcinoma: Current status and future directions. Clin Cancer Res 13: 1098-1106, 2007.

37. Scappacticci FA, Skillings JR, Holden SN, Gerber HP, Miller K Kabbinavar F, Bergsland E, Ngai J, Kolmangren E, Wang J and Hurwitz H: Arterial thromboembolic events in patients with metastatic carcinoma treated with chemotherapy and bevacizumab. J Natl Cancer Inst 99: 1232-1239, 2007.

38. Hurwitz HI, Fehrenbacher L, Hainsworth JD, Heim W, Berlin J, Holmgren E, Hambleton J, Novotny WF and Kabbinavar F: Bevacizumab in combination with fluorouracil and leucovorin: An active regimen for first-line metastatic colorectal cancer. $\mathrm{J}$ Clin Oncol 23: 3502-3508, 2005.

39. Miller KD, Chap LI, Holmes FA, Cobleigh MA, Marcom PK, Fehrenbacher L, Dickler M, Overmoyer BA, Reimann JD, Sing AP, et al: Randomized phase III trial of capecitabine compared with bevacizumab plus capecitabine in patients with previously treated metastatic breast cancer. J Clin Oncol 23: 792-799, 2005

40. Johnson DH, Fehrenbacher L, Novotny WF, Herbst RS, Nemunaitis JJ, Jablons DM, Langer CJ, DeVore RF III, Gaudreault J, Damico LA, et al: Randomized phase II trial comparing bevacizumab plus carboplatin and paclitaxel with carboplatin and paclitaxel alone in previously untreated locally advanced or metastatic non-small-lung cancer. J Clin Oncol 22 2184-2191, 2004

41. Hurwitz H and Saini S: Bevacizumab in the treatment of metastatic colorectal cancer: Safety profile and management of adverse events. Semin Oncol 33 (5 Suppl 10): S26-S34, 2006.

42. Hurwitz H, Fehrenbacher L, Novotny W, Cartwright T, Hainsworth J, Heim W, Berlin J, Baron A, Griffing S, Holmgren E, et al: Bevacizumab plus irinotecan, fluorouracil, and leucovorin for metastatic colorectal cancer. N Engl J Med 350: 2335-2342, 2004.

43. Pande A, Lombardo J, Spangenthal E and Javle M: Hypertension secondary to anti-angiogenic therapy: Experience with bevacizumab. Anticancer Res 27: 3465-3470, 2007.

44. Yeh ET, Tong AT, Lenihan DJ, Yusuf SW, Swafford J, Champion C, Durand JB, Gibbs H, Zafarmand AA and Ewer MS: Cardiovascular complications of cancer therapy: Diagnosis, pathogenesis and management. Circulation 109: 3122-3131, 2004

45. D'Adamo DR, Anderson SE, Albritton K, Yamada J, Riedel E, Scheu K, Schwartz GK, Chen H and Maki RG: Phase II study of doxorubicin and bevacizumab for patients with metastatic soft-tissue sarcomas. J Clin Oncol 23: 7135-7142, 2005. 
46. Karp JE, Gojo I, Pili R, Gocke CD, Greer J, Guo C, Qian D, Morris L, Tidwell M, Chen H, et al: Targeting vascular endothelial growth factor for relapsed and refractory adult acute myelogenous leukemias: Therapy with sequential 1-beta-d-arabinofuranosylcytosine, mitoxantrone, and bevacizumab. Clin Cancer Res 10: 3577-3585, 2004.

47. Nalluri SR, Chu D, Keresztes R, Zhu X and Wu S: Risk of venous thromboembolism with the angiogenesis inhibitor bevacizumab in cancer patients: A meta-analysis. JAMA 300: 2277-2285, 2008.

48. Laitinen M, Zachary I, Breier G, Pakkanen T, Häkinen T, Luoma J, Abedi H, Risau W, Soma M, Laakso M, et al: VEGF gene transfer reduces intimal thickening via increased production of nitric oxide in carotid arteries. Hum Gene Ther 8: 1737-1744, 1997.

49. Levy BI, Ambrosio G, Pries AR and Struijker-Boudier HA Microcirculation in hypertension: A new target for treatment? Circulation 104: 735-740, 2001.

50. Hesser BA, Liang XH, Camenisch G, Yang S, Lewin DA, Scheller R, Ferrara N and Gerber HP: Down syndrome critical region protein 1 (DSCR1), a novel VEGF target gene that regulates expression of inflammatory markers on activated endothelial cells. Blood 104: 149-158, 2004.

51. Kuenen BC, Levi M, Meijers JC, Kakkar AK, van Hinsbergh VW, Kostense PJ, Pinedo HM and Hoekman K: Analysis of coagulation cascade and endothelial cell activation during inhibition of vascular endothelial growth factor/vascular endothelial growth factor receptor pathway in cancer patients. Arterioscler Thromb Vasc Biol 22: 1500-1505, 2002.

52. Whittle BJ, Moncada S and Vane JR: Comparison of the effects of prostacyclin (PGI2), prostaglandin E1 and D2 on platelet aggregation in different species. Prostaglandins 16: 373-388, 1978 .

53. Izumiya Y, Shiojima I, Sato K, Sawyer DB, Colucci WS and Walsh K: Vascular endothelial growth factor blockade promotes the transition from compensatory cardiac hypertrophy to failure in response to pressure overload. Hypertension 47: 887-893, 2006.

54. Cheng $\mathrm{H}$ and Force T: Why do kinase inhibitors cause cardiotoxicity and what can be done about it? Prog Cariovasc Dis 53 114-120, 2010

55. Cheng $\mathrm{H}$ and Force T: Molecular mechanisms of cardiovascular toxicity of targeted cancer therapeutics. Circ Res 106: 21-34, 2010.

56. Kerkela R, Woulfe KC, Durand JB, Vagnozzi R, Kramer D, Chu TF, Beahm C, Chen MH and Force T: Sunitinib-induced cardiotoxicity is mediated by off-target inhibition of AMP-activated protein kinase. Clin Transl Sci 2: 15-25, 2009.

57. Kerkela R, Grazette L, Yacobi R, Illiescu C, Patten R, Beahm C, Walters B, Shevtsov S, Pesant S, Clubb FJ, et al: Cardiotoxicity of the cancer therapeutic agent imatinib mesylate. Nat Med 12: 908-16, 2006.

58. Talpaz M, Shah NP, Kantariian H, Donato N, Nicoll J, Paquette R, Cortes J, O'Brien S, Nicaise C, Bleickardt E, et al: Dasatinib in imatinib-resistant Philadelphia chromosome-positive leukemias. N Engl J Med 354: 2531-2541, 2006.

59. Deming PB, Schafer ZT, Tashker JS, Potts MB, Deshmukh M and Kornbluth S: Bcr-Abl-mediated protection from apoptosis downstream of mitochondrial cytochrome $c$ release. Mol Cell Biol 24: 10289-10299, 2004.

60. Beininger M, Buchdunger E and Druker BJ: The development of imatinib as a therapeutic agent for chronic myeloid leukemia. Blood 105: 2640-2653, 2005.

61. Cohen MH, Williams G, Johnson JR, Duan J, Gobburu J, Rahman A, Benson K, Leighton J, Kim SK, Wood R, et al: Approval summary for imatinib mesylate capsules in the treatment of chronic myelogenous leukemia. Clin Cancer Res 8 : 935-942, 2002

62. Atallah E, Durand JB, Kantarjian H and Cortes J: Congestive heart failure is a rare event in patients receiving imatinib therapy. Blood 110: 1233-1237, 2007.

63. Hatfield A, Owen S and Pilot PR: In reply to 'Cardiotoxicity of the cancer therapeutic agent imatinib mesylate'. Nat Med 13: 13 author reply 15-16, 2007.

64. Rosti G, Martinelli G and Baccarani M: In reply to 'Cardiotoxicity of the cancer therapeutic agent imatinib mesylate'. Nat Med 13: 15 ; author reply $15-16,2007$.
65. Gambacorti-Passerini C, Tornaghi L, Franceschino A, Piazza R, Corneo G and Pogliani E: In reply to 'Cardiotoxicity of the cancer therapeutic agent imatinib mesylate'. Nat Med 13: 13-14; author reply 15-16, 2007.

66. Atallah E, Kantarjian H and Cortes J: In reply to 'Cardiotoxicity of the cancer therapeutic agent imatinib mesylate'. Nat Med 13: 14; author reply 15-16, 2007.

67. Fernández A, Sanguino A, Peng Z, Crespo A, Ozturk E, Zhang X, Wang S, Bornmann W and Lopez-Berestein G: Rational drug redesign to overcome drug resistance in cancer therapy: Imatinib moving target. Cancer Res 67: 4028-4033, 2007.

68. Demetri GB: Structural reengineering of imatinib to decrease cardiac risk in cancer therapy. J Clin Invest 117: 3650-3653, 2007.

69. Bearzi C, Rota M, Hosoda T, Tillmanns J, Nascimbene A, De Angelis A, Yasuzawa-Amano S, Trofimova I, Siggins RW, Lecapitaine N, et al: Human cardiac stem cells. Proc Natl Acad Sci USA 104: 14068-14073, 2007.

70. Ghoreschi K, Laurence A and O'Shea JJ: Selectivity and therapeutic inhibition of kinases: To be or not to be? Nat Immunol 10: 356-360, 2009.

71. U.S. Food and Drug Administration: FDA approves new treatment for gastrointestinal and kidney cancer. www.fda. gov/NewsEvents/Newsroom/PressAnnouncements/2006/ ucm108583.htm Accessed January 26, 2006.

72. Young E, Miele L, Tucker KB, Huang M, Wells J and Gu JW: SU11248, a selective tyrosine kinases inhibitor suppresses breast tumor angiogenesis and growth via targeting both tumor vasculature and breast cancer cells. Cancer Biol Ther 10: 703-711, 2010.

73. Xin H, Zhang C, Herrmann A, Du Y, Figlin R and Yu H: Sunitinib inhibition of Stat 3 induces renal cell carcinoma tumor cell apoptosis and reduces immunosuppressive cell. Cancer Res 69: 2506-2513, 2009

74. Pal SK, Figlin RA and Yu H: Deciphering the anticancer mechanisms of sunitinib. Cancer Biol Ther 10: 712-714, 2010

75. Telli ML, Witteles RM, Fisher GA and Srinivas S: Cardiotoxicity associated with the cancer therapeutic agent sunitinib malate. Ann Oncol 19: 1613-1618, 2008.

76. Motzer RJ, Hutson TE, Tomczk P, Michaelson MD, Bukowski RM, Rixe O, Oudard S, Negrier S, Szczylik C, Kim ST, et al: Sunitinib versus interferon alfa in metastatic renal-cell carcinoma. N Engl J Med 356: 115-124, 2007.

77. Demetri GD, van Oosterom AT, Garrett CR, Blackstein ME, Shah MH, Verweij J, McArthur G, Judson IR, Heinrich MC, Morgan JA, et al: Efficacy and safety of sunitinib in patients with advanced gastrointestinal stromal tumour after failure of imatinib: A randomized controlled trial. Lancet 368: 1329-1338, 2006.

78. Edelberg JM, Lee SH, Kaur M, Tang L, Feirt NM, McCabe S, Bramwell O, Wong SC and Hong MK: Platelet-derived growth factor-AB limits the extent of mycocardial infarction in a rat model: Feasibility of restoring impaired angiogenic capacity in the aging heart. Circulation 105: 608-613, 2002.

79. Chintalgattu V, Ai D, Langley RR, Zhang J, Bankson JA, Shih TL, Reddy AK, Coombes KR, Daher IN, Pati S, et al: Cardiomyocyte PDGFR-beta signaling is an essential component of the mouse cardiac response to load-induced stress. J Clin Invest 120: 472-484, 2010.

80. Rini BI, Cohen DP, Lu DR, Chen I, Hariharan S, Gore ME, Figlin RA, Baum MS and Motzer RJ: Hypertension as a biomarker of efficacy in patients with metastatic renal cell carcinoma treated with sunitinib. J Natl Cancer Inst 103: 763-773, 2011.

81. Fleisher LA, Fleischmann KE, Auerbach AD, Barnason SA, Beckman JA, Bozkurt B, Davila-Roman VG, Gerhard-Herman MD, Holly TA, Kane GC, Marine JE, Nelson MT, Spencer CC, Thompson A, Ting HH, Uretsky BF, Wijeysundera DN; American College of Cardiology; American Heart Association: 2014 ACC/AHA guideline on perioperative cardiovascular evaluation and management of patients undergoing noncardiac surgery: a report of the American College of Cardiology/American Heart Association Task Force on practice guidelines. J Am Coll Cardiol 64: e77-e137, 2014. 